\title{
Colonization by Helicobacter pylori of leprosy patients in Spain: immunomodulation to low molecular weight antigens of $\boldsymbol{H}$. pylori
}

\author{
Neluka Fernandoํ, Pedro Torres², Dino Vaira ${ }^{3}$, John Holton ${ }^{4}++$ \\ ${ }^{1}$ Department of Microbiology, Faculty of Medical Sciences, University of Sri Jayewardenapura, Nugegoda, Sri Lanka ${ }^{2}$ Sanatorium San \\ Francisco de Borja, Fontilles, Spain ${ }^{3}$ First Medical Clinic, St. Orsola Hospital, University of Bologna, Bologna, Italy ${ }^{4}$ Department of Clinical \\ Microbiology, Windeyer Institute of Medical Science, University College London Hospital Trust, 46 Cleveland St., W1T 4JF London, UK \\ We studied the prevalence of Helicobacter pylori in patients with leprosy and the effects of co-infection on the \\ immune response to Helicobacter antigens in the polar groups of leprosy (lepromatous and tuberculoid). We showed \\ that there is no difference in the prevalence of $\mathrm{H}$. pylori in patients with leprosy as compared to a non-leprosy popu- \\ lation. We also demonstrated that the immune response to low molecular weight $\mathrm{H}$. pylori antigens $(35,26$ and 19 \\ $k D a)$ differs in patients with lepromatous as compared to those with tuberculoid leprosy. In lepromatous leprosy, we \\ show that there is a higher prevalence of the 35 and $26 \mathrm{kDa}$ antigens, but a lower prevalence of the $19 \mathrm{kDa}$ antigen. \\ These immunological results are consistent with previous histopathological studies illustrating a more severe gas- \\ trointestinal inflammation in lepromatous patients; importantly, a response to the $35 \mathrm{kDa}$ antigen is recognized as \\ a marker for the development of ulcerative disease.
}

Key words: leprosy - Helicobacter pylori - immunomodulation

The purpose of this study was to investigate whether there was a difference in the prevalence of Helicobacter pylori between patients with leprosy and non-leprosy controls and whether the immune response to $H$. pylori differed in the two polar groups of leprosy (lepromatous and tuberculoid). An additional aim was to determine whether there was any specific clinical significance of $H$. pylori colonization of leprosy patients.

Immune response to Mycobacterium leprae infection - Leprosy is a polar disease. At one end of the clinicopathological spectrum is lepromatous leprosy (LL), in which large numbers of organisms are present in the dermis. In LL, the immune response is characterized by a TH2 cell profile, no granulomas are seen via histology and the clinical presentation is characterized by multiple skin lesions. At the other end of the spectrum is tuberculoid leprosy (TL), in which there are few bacilli and welldefined granulomas, the immune response is characterized by TH1 cytokines and few skin lesions are present.

Immune response to $H$. pylori infection - Colonization by $H$. pylori is associated with peptic ulcer disease, gastric adenocarcinoma, mucosa-associated lymphoid tissue lymphoma and a variety of immune-related extragastrointestinal diseases. Infection leads to a strong antibody and cellular immune TH1 response. Despite this response, the host's immune system cannot eradicate the organism and a chronic inflammation ensues.

Financial support: Department of Clinical Microbiology, University College London Hospital

+ Corresponding author: john.holton@uclh.nhs.uk

Received 17 December 2009

Accepted 26 May 2010
Western blotting of sera from patients with various clinical outcomes of $H$. pylori-related disease has demonstrated that a serological response to the $33-35 \mathrm{kDa}$ antigen was present in $97.5 \%$ of patients with peptic ulcer disease as compared to $70 \%$ in those with chronic gastritis (Yamaoka et al. 1998). Further studies of the serological response in 182 subjects with $H$. pylori infection confirmed this association in Africa (Lamarque et al. 1999), Thailand (Vilaichone et al. 2003) and France (Delchier et al. 2001). An additional study has demonstrated that the simultaneous presence of a $19.5 \mathrm{kDa}$ antibody and absence of the antibody to the $35 \mathrm{kDa}$ antigen was associated with an increased risk of gastric cancer Chomvarin et al. (2009).

H. pylori infection in leprosy patients - There have been very few investigations of $H$. pylori co-infection of patients with leprosy. An endoscopic study of long-term leprosy patients compared to controls indicated a greater degree of chronic gastritis, atrophy and intestinal metaplasia in the leprosy patients irrespective of the treatment received. However, the sero-positive rate for $H$. pylori did not differ between the groups. There were 14 cases of gastric carcinoma Maeda et al. (1997).

A later endoscopic study of 104 patients and 100 controls demonstrated that $H$. pylori, inflammation and atrophy were more common in leprosy patients compared to non-leprosy controls; furthermore, there was a decreasing trend toward colonization and inflammation from tuberculoid to lepromatous poles of leprosy. In addition, there was an increasing trend toward atrophy from tuberculoid to lepromatous poles of leprosy Misra et al. (2001).

This study extends the work by Maeda et al. (1997) and Misra et al. (2001) and demonstrates that in lepromatous patients there is a more frequent antibody response to low molecular weight antigens ( 35 and $26 \mathrm{kDa}$ ), but a less frequent response to the $19 \mathrm{kDa}$ antigen as compared to 
tuberculoid patients or a control population. The clinical significance of this result has not yet been determined.

\section{PATIENTS, MATERIALS AND METHODS}

Recruitment of patients was performed in Spain by Dr. Pedro Torres (Sanatorium San Francisco de Borja, Fontilles, Spain). Fifty patients (male $=30$; female $=20$; age range 40-83; mean of 65 years) with leprosy were studied. Forty-nine elderly patients (male $=17$; female $=32$; age range 53-96; mean of 74 years) who did not have leprosy but were cared for in the same Sanatorium, although housed in a different hospital building, were the control population. All patients gave their informed consent for the study and the local Ethical Committee approved the study in accordance with the Helsinki Declaration of Human Rights 1983.

Leprosy population - Thirty-seven of the patients $($ male $=22$; female $=15)$ had multi-bacillary disease with the typical histological appearance of LL and 13 patients (male $=7$; female $=6$ ) had TL disease with the histological appearances of borderline TL at first diagnosis. The time of the initial diagnosis ranged from 1976-1985. The most recent histology taken on these patients (19941997) showed skin and nasal smears to be mycobacterianegative in both the LL and borderline TL cases. The histological identity of each patient was obtained from the patients' records.

All subjects at the initial diagnosis had been given the current recommended therapy (usually rifampicin and clofazamine for 2 years), but any subject who was given antibiotics, anti-secretory agents or steroids within one year of this study were excluded. Many of the patients had other medical conditions in addition to leprosy; 10 had chronic hepatitis, three had renal failure, six had hypertension, one had diabetes and four had peptic ulcers with three cases of atrophic gastritis. Several of the patients had arthritis or chronic obstructive airway disease.

Clinical control population - The clinical control population consisted of geriatric patients from the surrounding area who had a number of medical conditions requiring hospitalization or who was admitted because they could not cope. Many had more than one medical condition. The most frequent illnesses were cardiovascular disease (hypertension, angina or a cerebro-vascular accident), senile dementia or Parkinson's disease, arthritis, chronic obstructive airway disease, diabetes and cancer. Other patient conditions were alcoholism, fractures, epilepsy, syphilis and depression. Two patients had peptic ulcers. All subjects who had received antibiotics, anti-secretory agents or steroids within the year preceding the study were excluded.

Faecal antigen study - Eighty-four faecal specimens were processed using an enzyme immunoassay for the detection of the faecal antigen for H. pylori - $\mathrm{HpSA}^{\mathrm{TM}}$ (Meridian Diagnostics, USA). The test was performed according to the manufacturer's instructions and a positive result indicated current colonization.

Sero-prevalence of $H$. pylori - The presence of $\operatorname{IgG}$ to $H$. pylori was determined using SIA ${ }^{\mathrm{TM}} H$. pylori $(\mathrm{HM}-$
$\mathrm{CAP}^{\mathrm{TM}}$, Sigma, UK) according to the manufacturer's instructions and the presence of IgG antibodies to CagA was determined using Helori CTX (Eurospital, Italy) according to the manufacturers' instructions and interpreted as described. Immunoglobulin $\mathrm{G}$ antibodies to $H$. pylori urease/heat shock protein (hsp) and lipopolysaccharide (LPS) were determined using an in-house assay.

Extraction of H. pylori LPS - Extraction of LPS was performed by phenol-water extraction as originally described by Westphal and Jann (1965). Briefly, H. pylori NCTC 11367 was grown on 20 plates of Columbia horse blood agar (Oxoid, UK) in an atmosphere of $5-15 \% \mathrm{O}_{2}$ and $10 \% \mathrm{CO}_{2}$ at $37^{\circ} \mathrm{C}$ for five days; bacteria were scraped off and suspended in $20 \mathrm{~mL}$ of distilled water and centrifuged at 2,000 $\mathrm{g}$ for $20 \mathrm{~min}$. The sediment was suspended in $35 \mathrm{~mL}$ of water and placed in an equal volume of $90 \%$ phenol (Merck, UK), pre-heated to $65-68^{\circ} \mathrm{C}$ and was added with vigorous stirring for 10-15 min. After cooling to about $10^{\circ} \mathrm{C}$ in an ice bath, the emulsion was centrifuged at 3,000 $\mathrm{g}$ for $30-45 \mathrm{~min}$. The water phase (containing LPS) was removed and dialyzed for 3-4 days against distilled water to remove phenol and any low molecular weight bacterial substances. This solution was then concentrated to about $5 \mathrm{~mL}$ and freeze-dried (Hetovac, Heto Lab Equipment, UK). The extracted LPS was electrophorezed on a $12 \%$ polyacrylamide gel and silver stained to determine the LPS step ladder pattern using the Bio-Rad Silver stain kit (Bio-Rad, UK) (Tsai \& Frasch 1982).

Extraction of Helicobacter urease (Dunn et al. 1990) - H. pylori was grown on 20 plates of Columbia horse blood agar (Oxoid, UK). The bacteria were harvested, kept on ice and centrifuged at $5,000 \mathrm{~g}$ for $20 \mathrm{~min}$ at $4^{\circ} \mathrm{C}$. The sediment was suspended in $30 \mathrm{~mL}$ of distilled water and vortexed for 45-60 s. The cells were sedimented by centrifugation at $10,000 \mathrm{~g}$ for $20 \mathrm{~min}$ at $4^{\circ} \mathrm{C}$. The supernatant was concentrated using a 100,000 centri-plus (Millipore, UK). Gel electrophoresis was performed to determine the molecular weight of the substances extracted. The protein concentration was estimated by the method of Warburg and Christian (1941).

In-house sero-assay - The antigen concentrations for both urease and LPS to be used in the enzyme linked immunosorbent assay (ELISA) were determined using a checkerboard titration with positive and negative reference sera.

The antigen was coated onto micro-titre plates (Nunc, UK) in $\mathrm{NaHCO}_{3}$ buffer (pH 9.6, $100 \mu \mathrm{L} /$ per well) by incubation at $37^{\circ} \mathrm{C}$ for $2 \mathrm{~h}$. Plates were washed three times with $1 \%$ phosphate buffered saline (PBS), Tween-20 and were blocked with $1 \%$ bovine serum albumin (BSA) in PBS overnight at $4^{\circ} \mathrm{C}$. The following day, the plates were washed again three times and the patients' serum (diluted $1: 100$ in $1 \%$ BSA/PBS) was added $(100 \mu \mathrm{L} /$ well) and incubated for $2 \mathrm{~h}$ at room temperature (RT). Plates were washed three times and antigen-bound $\mathrm{IgG}$ antibodies were detected with peroxidase-conjugated secondary antibody (Goat anti-human IgG, Sigma, UK) by incubating at $4^{\circ} \mathrm{C}$ overnight. The following day, plates were washed 
TABLE I

Immunological responses as seen with Western blot

\begin{tabular}{|c|c|c|c|c|}
\hline $\begin{array}{l}\text { Protein bands } \\
(\mathrm{kDa})\end{array}$ & Control & Leprosy & LL & $\mathrm{TL}$ \\
\hline 120 & $32 / 49$ & $26 / 50$ & $20 / 37$ & $6 / 13$ \\
\hline 89 & $28 / 49$ & $22 / 50$ & $18 / 37$ & $4 / 13$ \\
\hline 35 & $21 / 49$ & $28 / 50$ & $25 / 37$ & $3 / 13$ \\
\hline 30 & $33 / 49$ & $30 / 50$ & $22 / 37$ & $8 / 13$ \\
\hline 26 & $31 / 49$ & $26 / 50$ & $23 / 37$ & $3 / 13$ \\
\hline 19 & $26 / 49$ & $14 / 50$ & $13 / 37$ & $1 / 13$ \\
\hline
\end{tabular}

LL: lepromatous leprosy; TL: tuberculoid leprosy.

three times, 2,2'-azino-bis-(3-ethylbenzthiazoline-6-sulfonic acid) was added for $20 \mathrm{~min}$, the reaction was stopped with Stop solution and the optical density (OD) was read at $650 \mathrm{~nm}$ using an ELISA reader (Dynatech MR500, UK). The average OD values of the background (antigen + conjugate + substrate) control wells were determined and this was deducted from all experimental results. For each of the different populations tested, the cut-off was determined by using 20 known negative sera from healthy individuals from that population and was defined as the mean \pm 2 standard deviation. All tests were carried out with a background control (antigen + conjugate + substrate), a positive control and a negative control.

Western blot analysis - Immunoglobulin G antibodies to six antigens of $H$. pylori were tested using an inhouse assay. H. pylori strain NCTC 11637 was grown for five days on 10 plates of Columbia horse blood agar (Oxoid, UK). The bacteria were scraped off into $5 \mathrm{~mL}$ of distilled water, chilled on ice and sonicated using a Vibra cell sonicator at an amplitude of 60 prm for $6 \mathrm{~min}$. The protein concentration was estimated by the method of Warburg and Christian (1941). The appropriate concentration of antigen $(50 \mu \mathrm{g})$ (after checkerboard titration) was determined and used in preparation of the western blot strips. The primary antibody (patients' serum) was diluted at $1: 100$ in $1 \%$ milk and $800 \mu \mathrm{L}$ was added to each strip. These were placed in a Bio-Rad tray and incubated on a shaker for $2 \mathrm{~h}$ at RT. Blots were washed three times in PBS/BSA/Tween-20 for 5 min with a final wash in distilled water.

The secondary antibody, peroxidase-conjugated immunoglobulin to human IgG (Harlan, UK), was diluted 1:1000 in PBS/BSA/Tween-20, poured into wells and incubated for $1 \mathrm{~h}$ on a shaker.

The strips were washed, given a final wash in PBS and rinsed in distilled water. The bands were detected with chloro-napthol solution (made just before use) for $20 \mathrm{~min}$ at RT. Once the color developed, the dye was removed by rinsing the strips in tap water. The blots were dried, placed along the markers and stored.

Reading of results - Six to seven commonly noted prominent bands were studied. The presence or absence
TABLE II

Patterns of Western blot bands

\begin{tabular}{llllllll}
\hline Pattern $(\mathrm{kDa})$ & 1 & 2 & 3 & 4 & 5 & 6 & 7 \\
\hline 120 & + & + & + & & + & + & \\
89 & + & + & + & + & + & + & + \\
35 & + & + & & + & & & \\
30 & + & + & + & + & & + & + \\
26 & + & + & + & + & & & \\
19 & + & & & & + & & + \\
\hline
\end{tabular}

of bands was noted for each serum sample. The molecular weight of the bands was identified by electrophoresis with reference to known molecular weight marker proteins of 18-261 kDa (Blue RangerTM Pierce UK).

Statistical analysis - Measures of association were compared using the Chi-squared test. Multivariate analyses were assessed on the outcomes of ELISA for H. pylori $\mathrm{IgG}$ and HpSA for stool antigen using a logistic regression with leprosy groups combined against the control group and for each leprosy sub-group against the control. The outcome variables were compared with the independent variables: IgG to CagA, urease, LPS and the different bands on the western blots.

\section{RESULTS}

Immune response to specific $H$. pylori antigens Western blot analysis data characterizing reactivity to antigens of molecular weight $120 \mathrm{kDa}$ (CagA), $89 \mathrm{kDa}$ (VacA), 35 kDa (OipA), 30 kDa (UreH), 26 kDa (UreA) and $19 \mathrm{kDa}$ (UreE) are shown in Table I. Several combinations of bands were noted on the Western blots as illustrated in Table II. No bands were detected for those patients who were negative for active infection; in contrast, LL patients were more likely to have pattern 2 , although other patterns were also found. There was no statistical correlation between the banding patterns and type of leprosy; in contrast, there was a statistically sig- 
TABLE III

Immunological response and antigen detection

\begin{tabular}{|c|c|c|c|c|c|c|}
\hline Sample & Assay & $\mathrm{n}$ & $\begin{array}{c}\text { Control } \\
(\%)\end{array}$ & $\begin{array}{c}\text { Leprosy } \\
(\%)\end{array}$ & $\begin{array}{l}\text { LL } \\
(\%)\end{array}$ & $\begin{array}{l}\text { TL } \\
(\%)\end{array}$ \\
\hline Stools & $\mathrm{HpSA}^{\mathrm{TM}}$ & 84 & $\begin{array}{l}29 / 34 \\
(85.3)\end{array}$ & $\begin{array}{c}37 / 50 \\
(74)\end{array}$ & $\begin{array}{c}27 / 37 \\
(72)\end{array}$ & $\begin{array}{c}10 / 13 \\
(76)\end{array}$ \\
\hline Serum & $\begin{array}{c}\text { ELISA } \\
\text { SIA }^{\mathrm{TM}}\end{array}$ & 99 & $\begin{array}{l}44 / 49 \\
(89.8)\end{array}$ & $\begin{array}{l}47 / 50 \\
(72.3)\end{array}$ & $\begin{array}{l}34 / 37 \\
(91.9)\end{array}$ & $\begin{array}{l}13 / 13 \\
(100)\end{array}$ \\
\hline Serum & $\begin{array}{l}\text { ELISA } \\
\mathrm{CTX}^{\mathrm{TM}}\end{array}$ & 99 & $\begin{array}{l}20 / 49 \\
(40.3)\end{array}$ & $\begin{array}{c}27 / 50 \\
(54)\end{array}$ & $\begin{array}{l}21 / 37 \\
(56.8)\end{array}$ & $\begin{array}{c}6 / 13 \\
(46.2)\end{array}$ \\
\hline Serum & $\begin{array}{l}\text { ELISA }^{a} \\
\text { Ure/hsp }\end{array}$ & 99 & $\begin{array}{l}36 / 49 \\
(73.5)\end{array}$ & $\begin{array}{c}36 / 50 \\
(72)\end{array}$ & $\begin{array}{l}24 / 37 \\
(64.9)\end{array}$ & $\begin{array}{l}12 / 13 \\
(92.3)\end{array}$ \\
\hline Serum & $\begin{array}{c}\text { ELISA }^{a} \\
\text { LPS }\end{array}$ & 99 & $\begin{array}{l}19 / 49 \\
(38.8)\end{array}$ & $\begin{array}{c}15 / 50 \\
(30)\end{array}$ & $\begin{array}{c}10 / 37 \\
(27)\end{array}$ & $\begin{array}{c}5 / 13 \\
(38.5)\end{array}$ \\
\hline
\end{tabular}

fifteen patients in the control group failed to provide a faeces sample although all provided a serum sample. $a$ : in house ELISA assay; $\mathrm{CTX}^{\mathrm{TM}}$ : enzyme linked immunosorbent assay (ELISA) for detection of IgG antibodies to CagA positive Helicobacter pylori in serum; HpSA ${ }^{\mathrm{TM}}$ : ELISA for detection of $H$. pylori in faeces; LL: lepromatous leprosy; SIA ${ }^{\mathrm{TM}}$ : ELISA for detection of IgG antibodies to H. pylori in serum; TL: tuberculoid leprosy; Ure/hsp: urease/heat shock.

nificant difference in the presence of $35 \mathrm{kDa}, 26 \mathrm{kDa}$ and $19 \mathrm{kDa}$ bands between clinical groups.

There was a significantly higher odds ratio (OR) of a positive $35 \mathrm{kDa}$ band in the LL group as compared to the control group $[\mathrm{p}=0.01, \mathrm{OR}=4.6,95 \%$ confidence interval $(\mathrm{CI})=1.42-14.91]$ or the TL group $(\mathrm{p}=0.04$, $\mathrm{OR}=5.42,95 \% \mathrm{CI}=1.09-26.89)$. Similarly, there was a significantly higher likelihood of a positive $26 \mathrm{kDa}$ band in the LL and TL groups as compared to the control $(\mathrm{p}=0.01, \mathrm{OR}=5.99,95 \% \mathrm{CI}=17-30.80)$. There was a significantly lower likelihood of a positive Western blot-detectable band of $19 \mathrm{kDa}$ for the combined leprosy group vs. the control group $(\mathrm{p}=0.01, \mathrm{OR}=0.27,95 \% \mathrm{CI}$ $=0.11-0.68)$, the TL vs. the control group $(\mathrm{p}=0.003$, OR $=20.54,95 \% \mathrm{CI}=2.30-183.13$ ) and the LL group vs. the control group $(\mathrm{p}=0.05, \mathrm{OR}=0.25,95 \% \mathrm{CI}=0.09-0.76)$.

Prevalence of $H$. pylori - The sero-prevalence of $H$. pylori in the two populations and the two polar groups of leprosy patients is given in Table III. There were no statistically significant differences in the prevalence of H. pylori as detected by stool antigen or IgG to H. pylori between the control and leprosy group or between the LL and TL leprosy groups. The proportion of patients with an antibody response to CagA, urease/hsp and LPS failed to show any statistically significant differences in the three groups tested.

\section{DISCUSSION}

Both $H$. pylori-associated gastritis and leprosy are chronic infections with $H$. pylori eliciting a predominantly TH1-mediated response and affecting the stomach. On the other hand, leprosy elicits a polar TH1 or TH2 response and clinically affects mainly the skin and nerves.

In this study, the immune response and prevalence of $H$. pylori infection in a population of patients with leprosy was compared to a geriatric population from the same area of Spain and living in the same Sanatorium, though in separate hospital buildings. There were unavoidable minor differences in both populations, including a higher number of male leprosy patients, a lower number of male geriatric patients, and a mean age of 65 years for the leprosy patients, but a mean age of 74 years for the geriatric patients. Neither of these small differences is likely to have any influence on the prevalence of $H$. pylori in this population.

The levels of 26 and $35 \mathrm{kDa}$ bands were statistically significantly increased in LL patients. Antibody to the $19 \mathrm{kDa}$ protein was detected less frequently in LL patients as compared to the control group. The presence of the $35 \mathrm{kDa}$ protein is a marker for serious gastroduodenal disease, such as gastric and duodenal ulcer, and the presence of the $19 \mathrm{kDa}$ protein with the absence of the $35 \mathrm{kDa}$ is more common in cancer. The $35 \mathrm{kDa}$ antigen (OipA) is recognized as pro-inflammatory, although its function in Helicobacter is unknown, whereas the $19 \mathrm{kDa}$ antigen is an accessory protein (UreE) for Helicobacter urease that binds $\mathrm{Ni}$ atoms and is linked to cancer development. Its role here is unknown, but it may be involved in affecting cell signaling rather than being pro-inflammatory. The profile in this study is of an increased sero-response to the 26 and $35 \mathrm{kDa}$ antigens with less response to the $19 \mathrm{kDa}$ antigen, particularly in LL patients. The clinical significance of this is unclear but may imply that patients with LL are more likely to develop stomach ulceration as compared to TL or non-lepromatous patients. Two histological studies by Maeda et al. (1997) and Misra et al. (2001) confirm the greater degree of gastric pathology in leprosy patients and this may be associated with the host immune response to these particular Helicobacter antigens. The Helicobacter status in these two studies was not recorded.

No differences in the immune response to $H$. pylori antigens CagA, urease/hsp or LPS were noted among the 
control or either leprosy group. We demonstrated that patients with leprosy are no more or less likely to be colonized by $H$. pylori than a control population, as judged by the sero-prevalence and faecal antigen assay. Two cases of peptic ulcer disease were noted in the control population and four cases in the leprosy group, three of which also had atrophic gastritis. Steroids are often given to leprosy patients to control reversal reactions, although in this group of patients, steroids had not been given in the initial or subsequent treatment nor within one year of the study.

This study suggests that patients with LL are more likely to have an antibody response to the 26 and $35 \mathrm{kDa}$ antigens and thus may be at a high risk of developing Helicobacter-related gastroduodenal disease.

\section{ACKNOWLEDGEMENTS}

To Mr. J Eliyahoo, of the Research and Development Unit, University College Hospital London, for statistical analysis.

\section{REFERENCES}

Chomvarin C, Ottiwet O, Hahnvajanawong C, Intapan PM, Wongwajana S 2009. Seroreactivity to specific antigens of Helicobacter pylori infection is associated with an increased risk of the dyspeptic gastrointestinal diseases. Int J Infect Dis 13: 647-654.

Delchier JC, Lamarque D, Levy M, Tkoub EM, Copie-Bergman C, Deforges L, Chaumette MT, Haioun C 2001. Helicobacter pylori and gastric lymphoma: high seroprevalence of CagA in diffuse large B-cell lymphoma but not in low-grade lymphoma of mucosa associated lymphoid tissue type. Am J Gastroenterol 96: 2324-2328.

Dunn BE, Campbell GP, Perez-Perez GI, Blaser MJ 1990. Purification and characterization of urease from Helicobacter pylori. J Biol Chem 265: 9464-9469.
Lamarque D, Gilbert T, Roudot-Thoraval F, Deforges L, Chaumette MT, Delchier JC 1999. Seroprevalence of eight Helicobacter pylori antigens among 182 patients with peptic ulcer, MALT gastric lymphoma or non-ulcer dyspepsia. Higher rate of seroreactivity against $\mathrm{CagA}$ and $35-\mathrm{kDa}$ antigens in patients with peptic ulcer originating from Europe and Africa. Eur J Gastroenterol Hepatol 11: 721-726.

Maeda T, Ogawa K, Egawa K 1997. Clinico-pathological findings of gastrointestinal tract in leprosy patients. Nihon Hansenbyo Gakkai Zasshi 66: 91-96.

Misra V, Misra SP, Hatwal D, Dwivedi M, Singh KG, Bajaj AK 2001. Helicobacter pylori and associated histopathological changes in gastric biopsies of patients with leprosy. Indian J Pathol Microbiol 44: 271-275.

Tsai CM, Frasch CE 1982. A sensitive silver stain for detecting lipopolysaccharides in polyacrylamide gels. Anal Biochem 119: 115-119.

Vilaichone RK, Mahachai V, Kositchaiwat C, Graham DY, Yamaoka Y 2003. Relation between seroreactivity to low-molecularweight Helicobacter pylori-specific antigens and disease presentation. Clin Diagn Lab Immunol 10: 1025-1028.

Warburg O, Christian W 1941. Protein estimation. Biochem Zeitsohrift 310: 384.

Westphal O, Jann K 1965. Bacterial lipopolysaccharides: extraction with phenol-water and further applications of the procedure. In RL Whistler, ML Wolfrom (eds.), Methods in carbohydrate chemistry, Academic Press, New York, p. 83-91.

Yamaoka Y, Kodama T, Graham DY, Kashima K 1998. Search for putative virulence factors of Helicobacter pylori. The low-molecular-weight (33-35k) antigen. Dig Dis Sci 43: 1482-1487. 